\title{
Inclusion complexes of trihexyphenidyl with natural and modified cyclodextrins
}

\author{
Hideko Maeda, Risa Tanaka and Hirokazu Nakayama*
}

\begin{abstract}
The solubility of trihexyphenidyl (Thp) was improved by its combination with $\beta$-cyclodextrin ( $\beta-C D)$ and modified $\beta$-CDs. The solubility of Thp was found to be increased in the presence of $\beta-C D$, hydroxypropyl- $\beta$-cyclodextrin $(\mathrm{HP}-\beta-\mathrm{CD})$, methyl- $\beta$-cyclodextrin (Me- $\beta-\mathrm{CD})$ and sulfobutylether- $\beta$-cyclodextrin (SBE- $\beta$-CD). In particular, the solubility of Thp in conjunction with SBE- $\beta$-CD was increased by a factor of 11 . The formation constant $\left(K_{c}\right)$ for the Thp/SBE- $\beta$-CD inclusion complex was determined to be $2300 \mathrm{~L} / \mathrm{mol}$ based on fluorometry data. The structure of the Thp/SBE- $\beta-C D$ complex in aqueous solution was examined by ${ }^{1} \mathrm{H}-{ }^{1} \mathrm{H}$ rotating frame nuclear Overhauser effect spectroscopy (ROESY) NMR, and the phenyl moiety of the Thp was found to coordinate with the secondary hydroxyl face of the SBE- $\beta-C D$. A solid Thp/SBE- $\beta-C D$ inclusion complex was prepared by freeze-drying.
\end{abstract}

Keywords: Trihexyphenidyl; Sulfobutylether- $\beta$-cyclodextrin; Inclusion complexes; Spectrofluorometry; Solubility

\section{Introduction}

Trihexyphenidyl (Thp) is a pharmaceutical compound that has been shown to improve various disease symptoms, including muscle rigidity, finger tremors and depression, by regulating the release of adrenaline.

Natural cyclodextrins $(\alpha-, \beta$ - and $\gamma-\mathrm{CD})$ are widely used in many fields since they readily form inclusion complexes with a variety of organic compounds (Saenger 1980; ÖZdemir and Ordu 1998; Reineccius et al. 2002). As an example, $\beta$-cyclodextrin $(\beta-C D)$ is used to suppress the bitterness of antihistamine drugs in solution through the formation of inclusion complexes (Hibi et al. 1984; Ono et al. 2011). However, $\beta$-CD exhibits relatively low solubility in water, which limits its applications in pharmaceutical formulations. Therefore, various CD derivatives have been synthesized to extend the potential applications (Uekama 1985; Szejtli 1992; Loftsson and Duchêne 2007). We have previously reported complexes of $\alpha$-lipoic acid and melatonin with modified CD derivatives (Maeda et al. 2010, 2013), and determined that the solubilities of $\alpha$-lipoic acid and melatonin in the

\footnotetext{
* Correspondence: hiro@kobepharma-u.ac.jp

Department of Functional Molecular Chemistry, Kobe Pharmaceutical University, 4-19-1 Motoyamakita-machi, Higashinada-ku, Kobe 658-8558,
} Japan presence of sulfobutylether- $\beta$-CD increased by factors of 20 and 10 , respectively.

In the present work, we investigated the solubility of inclusion complexes of Thp with natural and modified CDs at constant $\mathrm{pH}$. To date, Thp complexes have not been assessed spectroscopically because of the low solubility of Thp. Haiyun et al. reported the evaluation of the complexation of rutin and $\beta-C D$ by fluorescence spectroscopy in a phosphate solution containing $2 \%(\mathrm{v} / \mathrm{v})$ methanol (Haiyun et al. 2003). Recently, Alvarez-Parrilla et al. reported stability constants for quercetin and rutin according to the methodology described by Haiyun (Alvarez-Parrilla et al. 2005). More recently, Al-Rawashdeh et al. reported the complexation of the sunscreen agents (oxybenzene, E2-ethylhexyl-methoxycinnamate, octocrylene) and $\beta$-CD by UV-Vis spectroscopy in methanol/water mixture. The results demonstrate that the formation of inclusion complexes of the sunscreen agents and $\beta$-CD can inhibit the photodegradation (Al-Rawashdeh et al. 2010, 2013). Therefore, this method using an organic solvent was used in the present study to allow determination of the formation constants $\left(K_{\mathrm{c}}\right)$ of Thp with various CDs.

The enantiodiscrimination of chiral Thp enantiomers by carboxylated methyls of $\alpha-, \beta$-, and $\gamma_{-} \mathrm{CD}$ was predicted by molecular docking study (Mulisa et al. 2014). More recently, structure of Thp/ $\beta$-CD was elucidated by

\section{Springer}


${ }^{1} \mathrm{H}$ NMR spectroscopic and computational methods (Ali and Shamim 2014).

The stability constant $(K)$ and $K_{\mathrm{c}}$ values of Thp with various CDs were obtained in a $50 \mathrm{mmol} \mathrm{pH} 7$ phosphate buffer containing ethanol. At present, there are no solubility data or spectroscopic data for such inclusion complexes at constant $\mathrm{pH}$ in the literature. Therefore, we first investigated the effect of the natural CDs and then examined a series of modified CDs: sulfobutylether- $\beta$ cyclodextrin (SBE- $\beta$-CD), hydroxypropyl- $\alpha$-cyclodextrin (HP- $\alpha$-CD), hydroxypropyl- $\beta$-cyclo dextrin (HP- $\beta$-CD), hydroxypropyl- $\gamma$-cyclodextrin (HP- $\gamma$-CD) and methyl $\beta-$ cyclodextrin (Me- $\beta-\mathrm{CD})$ on the solubility of Thp.

\section{Materials and methods Materials}

HP- $\alpha-C D, H P-\beta-C D, H P-\gamma-C D$ and Thp were purchased from Sigma-Aldrich (St. Louis, USA), $\alpha$-CD, $\beta$-CD and $\gamma$ CD were purchased from Wako Chemical (Tokyo, Japan) and SBE- $\beta-C D$ and Me- $\beta-C D$ were purchased from Cydex (Kansas, USA) and the Junsei Chemical Co., Ltd. (Tokyo, Japan), respectively.

\section{Phase solubility study}

$\mathrm{CD}$ solutions of varying concentrations were made in a 10:90 (v/v) ethanol/50 mmol phosphate buffer mixture and were combined with excess amounts of Thp, after which the solutions were stirred at $300 \mathrm{rpm}$ and $25^{\circ} \mathrm{C}$. The concentration of Thp in each solution was subsequently measured using a fluorescence spectrometer following 3, 17, 24, 48 and $72 \mathrm{~h}$. The data showed that an equilibrium concentration was obtained after $72 \mathrm{~h}$, and so at that point the solutions were filtered through a $0.45 \mu \mathrm{m}$ membrane. The concentration of Thp in each solution was determined based on fluorescence at $\lambda=$ $287 \mathrm{~nm}$ with excitation at $\lambda=257 \mathrm{~nm}$, using a Shimazu RF-5300PC spectrometer.

\section{Spectrometry}

The $\mathrm{pH}$ of each sample solution was maintained at 7 by the addition of a $50 \mathrm{mmol} / \mathrm{L}$ potassium dihydrogen phosphate buffer. A $5.0 \times 10^{-3} \mathrm{~mol} / \mathrm{L}$ solution of Thp in ethanol was prepared and used in all experimental trials. In these trials, a $1 \mathrm{~mL}$ aliquot of this stock solution was transferred into a $10 \mathrm{~mL}$ volumetric flask together with an appropriate amount of a $1.0 \times 10^{-2} \mathrm{~mol} / \mathrm{L}$ and $1.25 \times$ $10^{-2} \mathrm{~mol} / \mathrm{L} \mathrm{CD}$ phosphate solution, giving a final Thp concentration of $5.0 \times 10^{-4} \mathrm{~mol} / \mathrm{L}$ and $\mathrm{CD}$ concentrations of nil to $1.0 \times 10^{-2} \mathrm{~mol} / \mathrm{L}$. Each solution was subsequently filtered through a $0.45 \mu \mathrm{m}$ membrane. The fluorescence spectra of Thp $\left(5.0 \times 10^{-4} \mathrm{~mol} / \mathrm{L}\right)$ was measured in a 10:90 $(\mathrm{v} / \mathrm{v})$ ethanol $/ 50 \mathrm{mmol}$ phosphate buffer solution. The fluorescence intensity generated by the Thp was found to vary depending on the concentration of $\mathrm{CD}$ added.
Therefore, the value of $K_{c}$ could be obtained from the differences in the fluorescence intensities of the Thp/ $\mathrm{CD}$ solutions. Fluorescence spectra were recorded with a Shimazu RF-5300 PC spectrometer.

\section{Sample preparation}

Solid complexes of Thp and CDs were prepared by the following methods. Simple mixtures of Thp and CDs in solid form were prepared for comparison purposes.

\section{Physical mixing method}

Solid CD and Thp were combined at a ratio of $1 \mathrm{mmol}$ ( $2.16 \mathrm{~g}$ in the case of the SBE- $\beta$-CD) to $1 \mathrm{mmol}(0.3379 \mathrm{~g}$ for Thp) within a nylon bag, after which the mixture was shaken for $30 \mathrm{~min}$.

\section{Kneading method}

Solid CD and Thp were combined at a ratio of $1 \mathrm{mmol}$ (2.16 g for SBE- $\beta$-CD) to $1 \mathrm{mmol}(0.3379 \mathrm{~g}$ for Thp) together with a small amount of ethanol (ca. $3 \mathrm{~mL}$ ) and kneaded for $30 \mathrm{~min}$.

\section{Freeze-drying method}

Solid CD and Thp were combined at a ratio of $10 \mathrm{mmol}$ (1.08 $\mathrm{g}$ for SBE- $\beta$-CD) to $10 \mathrm{mmol}(0.168965 \mathrm{~g}$ for Thp) and dissolved in $50 \mathrm{~mL}$ of phosphate buffer ( $\mathrm{pH}$ 7), following which the water was removed under vacuum at $-40^{\circ} \mathrm{C}$.

\section{Analytical methods \\ ${ }^{1} \mathrm{H}$ NMR measurements}

A mixture of CD and Thp at a ratio of $10 \mathrm{mmol}(0.0216 \mathrm{~g}$ for SBE- $\beta-\mathrm{CD})$ to $10 \mathrm{mmol}$ (0.0034 $\mathrm{g}$ for Thp) was dissolved in $1 \mathrm{~mL}$ of $\mathrm{D}_{2} \mathrm{O}$ to allow for ${ }^{1} \mathrm{H}$ - and ${ }^{1} \mathrm{H}-{ }^{1} \mathrm{H}$ ROESY NMR measurements. When analyzing solely Thp, the compound was instead dissolved in $\mathrm{CD}_{3} \mathrm{OD}$ because of its poor solubility in water, using a ratio of $10 \mathrm{mmol}$ of Thp to $1 \mathrm{~mL}$ of $\mathrm{CD}_{3} \mathrm{OD}$.

${ }^{1} \mathrm{H}_{-}{ }^{1} \mathrm{H}$ ROESY NMR data were obtained in the phase sensitive mode under continuous wave $(\mathrm{CW})$ operation, with spin lock for mixing. Spectra of the inclusion complex were obtained by spin lock pulses of $180_{x}-180_{-x}$ with a steady-state sequence prior to $\mathrm{d} 1$, together with $[\mathrm{grad}]_{\mathrm{z}}-90_{\mathrm{x}}-[\mathrm{grad}]_{\mathrm{z}}$ pulses.

\section{$X$-ray diffraction (XRD)}

Powder XRD patterns were obtained using a Rigaku Denki (Tokyo, Japan) Rint 2000 diffractometer with Ni-filtered $\mathrm{Cu} \mathrm{K} \alpha$ radiation.

\section{Differential scanning calorimetry (DSC)}

The thermal behaviors of the solid complexes were assessed using a DSC 3100SA instrument (NETZSCH, 
Selb, Germany) at a heating rate of $10^{\circ} \mathrm{C} / \mathrm{min}$ from 25 to $500^{\circ} \mathrm{C}$.

\section{Results and discussion \\ Phase solubility}

The complexation of Thp in the presence of natural CDs and various modified CDs was examined using the solubility method (Higuchi and Connors 1965). Figure 1 shows the phase solubility diagram of various Thp/CD complexes at $25^{\circ} \mathrm{C}$ and $\mathrm{pH}$ 7. A considerable increase in the solubility of Thp was observed in the presence of $\beta-C D$ and the $\beta$-CD derivatives. In particular, in the presence of SBE- $\beta-C D$, the solubility of Thp was 11 times higher than that of Thp itself. Based on the Higuchi-Connors theory (Higuchi and Connors 1965), both $\beta-C D$ and the $\beta$-CD derivatives showed an $A_{L}$-type solubility curve, indicating the formation of soluble complexes. There was no improvement in the solubility when employing either $\alpha$-CD or HP- $\alpha$-CD, while the use of $\gamma$ $\mathrm{CD}$ and $\mathrm{HP}-\gamma-\mathrm{CD}$ approximately doubled the solubility of the Thp.

Table 1 summarizes the $K$ values calculated from regression analysis of the phase solubility curves, using Eq. (1). Note that $K$ values were not obtained for the $\gamma$-CD and
HP- $\gamma$-CD solutions since these solutions did not generate linear solubility curves.

$$
K=\frac{\text { slope }}{\text { intercept }(1-\text { slope })}
$$

The complexation ability of the SBE- $\beta$-CD appears to be the highest among the CDs investigated in this study.

\section{Spectrophotometry}

Solutions containing $1.0 \times 10^{-4} \mathrm{~mol} / \mathrm{L}$ of Thp and $1.0 \times$ $10^{-4} \mathrm{~mol} / \mathrm{L} \mathrm{SBE}-\beta-\mathrm{CD}$ were made in a 50:50 (v/v) etha$\mathrm{nol} / 50 \mathrm{mmol}$ phosphate buffer solution and samples for the preparation of a Job's plot were prepared by mixing these solutions in varying proportions. The resulting Job's plot (Job 1928) obtained from fluorescence intensity measurements of these Thp/SBE- $\beta$-CD solutions is presented in Figure 2 . The maximum [Thp] $\Delta$ Intensity value at $R=0.5$ indicates the formation of a complex in which the stoichiometry is $1: 1$. The stoichiometries of the other Thp/CD complexes were also found to be 1:1 using this same method.

Figure 3 shows the fluorescence spectra obtained for Thp in combination with various $\beta$-CD concentrations,

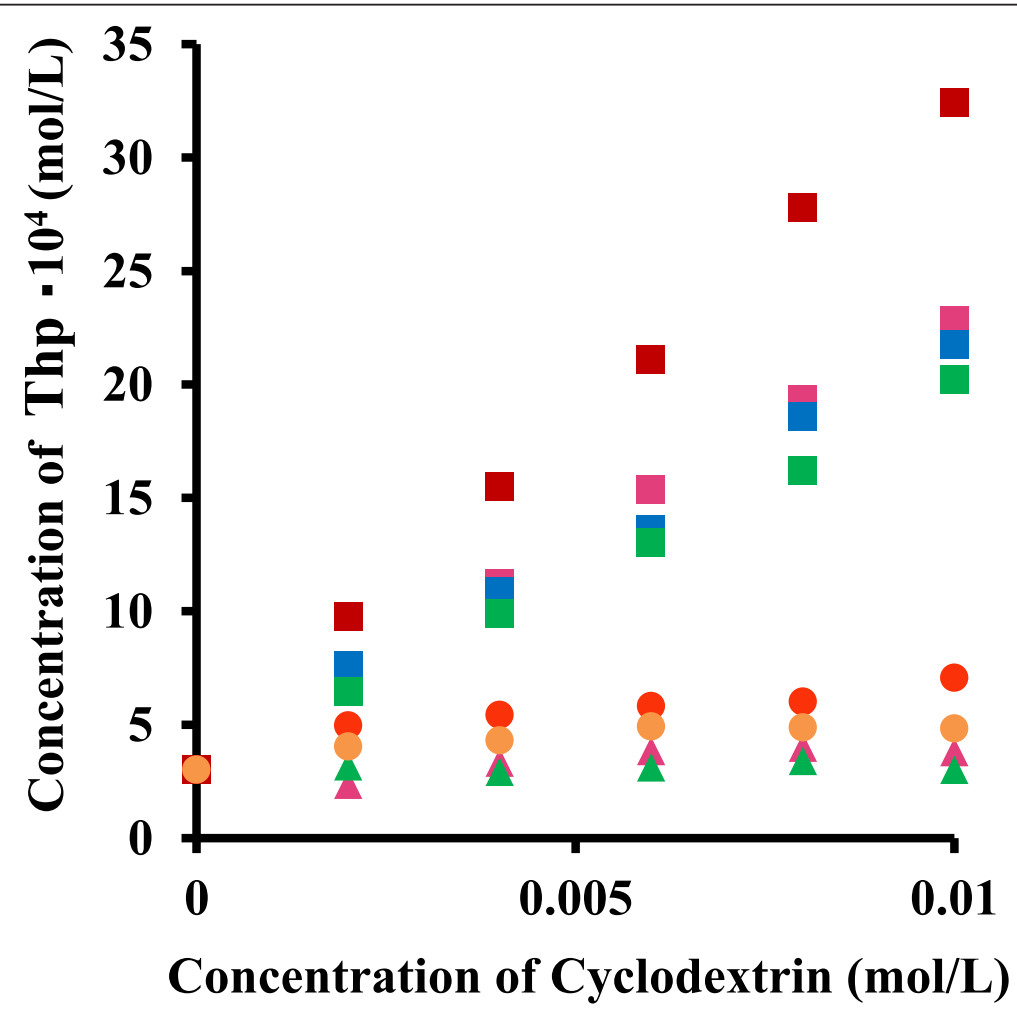

Figure 1 Phase solubility diagrams at $25^{\circ} \mathrm{C}$ and $\mathrm{pH}$ 7. The solubility of Thp in the presence of SBE- $\beta-C D$ (Red square), Me- $\beta$-CD (Blue square), $\mathrm{HP}-\beta-\mathrm{CD}$ (Green square), $\beta-\mathrm{CD}$ (Pink square), HP- $\gamma$-CD (Yellow circle), HP- $\alpha$-CD (Green triangle), $\alpha-C D$ (Pink triangle) and $\gamma$-CD (Red circle) are shown as a function of their concentration. 
Table 1 Regression parameters and stability constants $(K)$ for Thp/CD complexes as determined by solubility diagrams at $\mathrm{pH} 7$

\begin{tabular}{lllll}
\hline CD & Slope & Intercept & $\mathbf{R}^{\mathbf{2}}$ & $\boldsymbol{K}(\mathbf{L} / \mathbf{m o l})$ \\
\hline$\beta-C D$ & 0.199 & 3.14 & 0.999 & $800 \pm 50$ \\
HP- $\beta$-CD & 0.169 & 3.00 & 0.999 & $680 \pm 40$ \\
Me- $\beta$-CD & 0.185 & 3.33 & 0.994 & $680 \pm 80$ \\
SBE- $\beta-C D$ & 0.295 & 3.51 & 0.998 & $1200 \pm 200$ \\
\hline
\end{tabular}

in which the fluorescence intensity at $283 \mathrm{~nm}$ is seen to increase with increasing $\beta$-CD concentrations from nil to $1.8 \times 10^{-3} \mathrm{~mol} / \mathrm{L}$. From these data, the $K_{c}$ value of the complex of Thp with each CD could be determined from a plot of the reciprocal of $\Delta F$ against the reciprocal of [CD] according to Benesi's equation (Benesi and Hildebrand 1949), below.

$$
\frac{1}{\Delta F}=\frac{1}{\mathrm{a}[\mathrm{G}] \cdot K_{c}} \cdot \frac{1}{[\mathrm{CD}]}+\frac{1}{\mathrm{a}[\mathrm{G}]}
$$

Here $\Delta F$ is calculated as:

$$
\Delta F=F-F_{0}
$$

where $F$ and $F_{0}$ are the fluorescence intensities in the presence and absence of the $\mathrm{CD}$, respectively, while [G], $[C D]$ and a are the concentration of the guest compound (Thp), the concentration of the CD and a proportionality constant (Kondo et al. 1976; Hamai 1982), respectively.

The inset in Figure 3 demonstrates that a plot of $1 / \Delta F$ at $283 \mathrm{~nm}$ as a function of $1 /[\mathrm{CD}]$ for the $\beta-C D$ data generates a straight line that in turn gives a $K_{c}$ value of $1200 \mathrm{~L} / \mathrm{mol}$.

Figure 4 presents the fluorescence spectra obtained for Thp together with various $\mathrm{SBE}-\beta-\mathrm{CD}$ concentrations ranging from nil to $1.0 \times 10^{-2} \mathrm{~mol} / \mathrm{L}$, while the associated inset shows the data for SBE- $\beta$-CD concentrations from nil to $1.8 \times 10^{-3} \mathrm{~mol} / \mathrm{L}$. A plot of $1 / \Delta F$ at $283 \mathrm{~nm}$ against [CD] for these data again gives a straight line, from which a $K_{c}$ value of $2300 \mathrm{~L} / \mathrm{mol}$ was obtained.

Table 2 summarizes the $K_{c}$ values estimated from Eq. (2). Based on the data in Table 1, obtained using the solubility method, the original $\beta-\mathrm{CD}$ and the $\beta-\mathrm{CD}$ derivatives were all found to improve the solubility of the Thp. From the

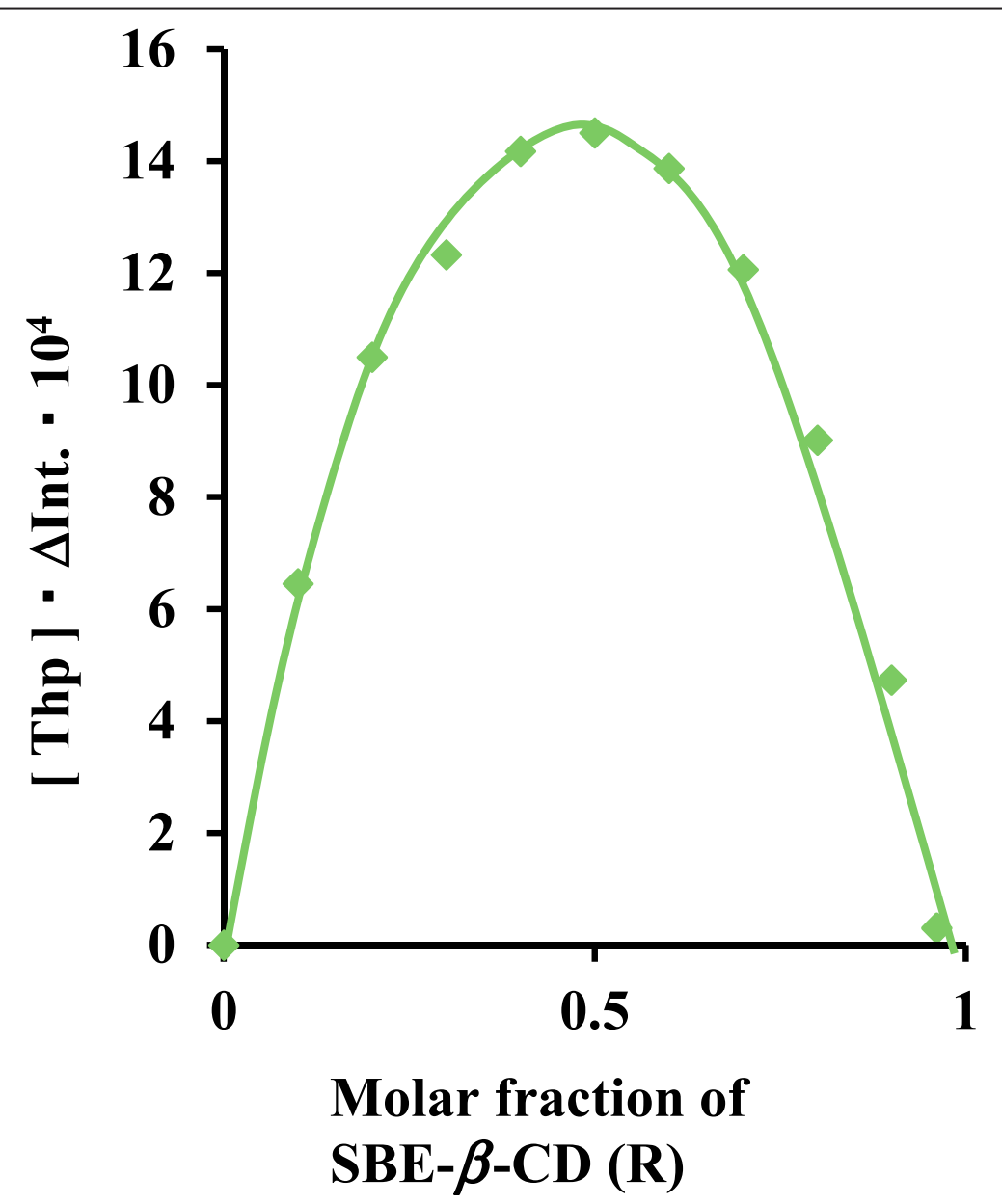

Figure 2 Job's plot of Thp/SBE- $\beta$-CD from fluorescence intensity measurements in a 50:50 ( $/ \mathrm{v})$ ethanol/50 mmol phosphate buffer solution. 


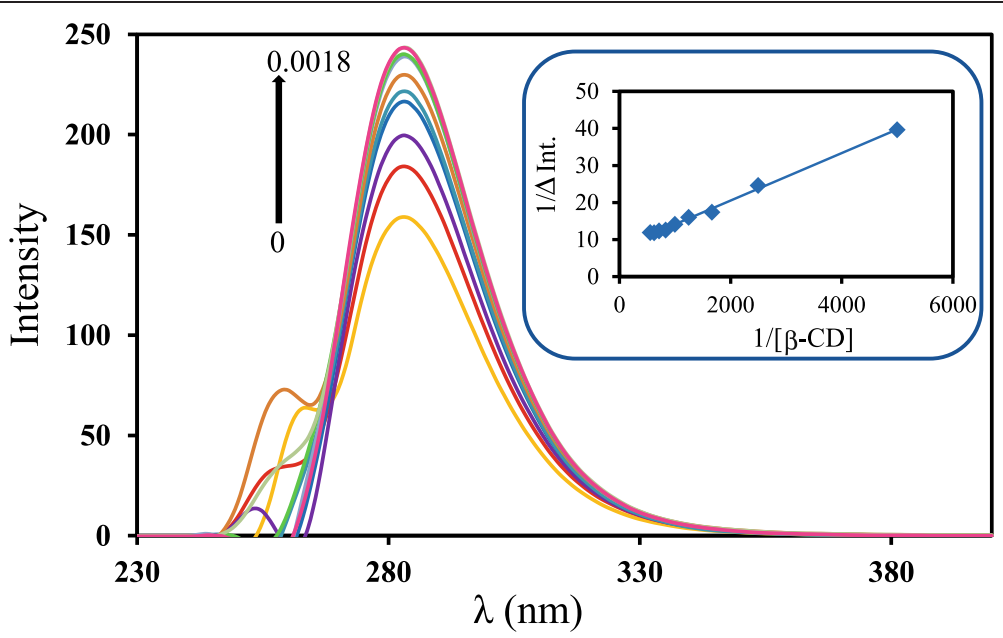

Figure 3 Fluorescence spectra of Thp in the presence of $\beta-C D$. The concentration of Thp is $5.0 \times 10^{-4} \mathrm{~mol} / \mathrm{L}$ and concentrations of $\beta$-CD are 0 , $0.2,0.4,0.6,0.8,1.0,1.2,1.4,1.6$ and $1.8 \times 10^{-3} \mathrm{~mol} / \mathrm{L}$ from bottom to top in $10: 90(\mathrm{v} / \mathrm{v})$ ethanol/50 $\mathrm{mmol}$ phosphate buffer solution. Inset shows their Benesi-Hildebrand plot for fluorescence increments at $283 \mathrm{~nm}$.

spectral data in Table 2, the complexation ability of the SBE- $\beta$-CD appears to be the highest among the CDs used in this study. Compared with our stability constants $(K)$ obtained by the solubility method, the $K_{c}$ values of Thp/ $\beta-C D$ and Thp/SBE- $\beta-C D$ was somewhat large, while the $K_{c}$ values of the Thp/Me- $\beta$-CD and Thp/HP- $\beta$-CD complexes are seen to be similar to the $K$ values obtained by the solubility method. Apparent stability constant estimated from solubility data has large error and has been used rough estimate of complex formation. Therefore, the difference between the stability constants obtained from solubility diagrams and spectroscopic has been sometimes recognized.

The solubility of Thp in the presence of SBE- $\beta$-CD was increased by a factor of 11 , and the stability of the resulting Thp/SBE- $\beta$-CD complex was higher than those

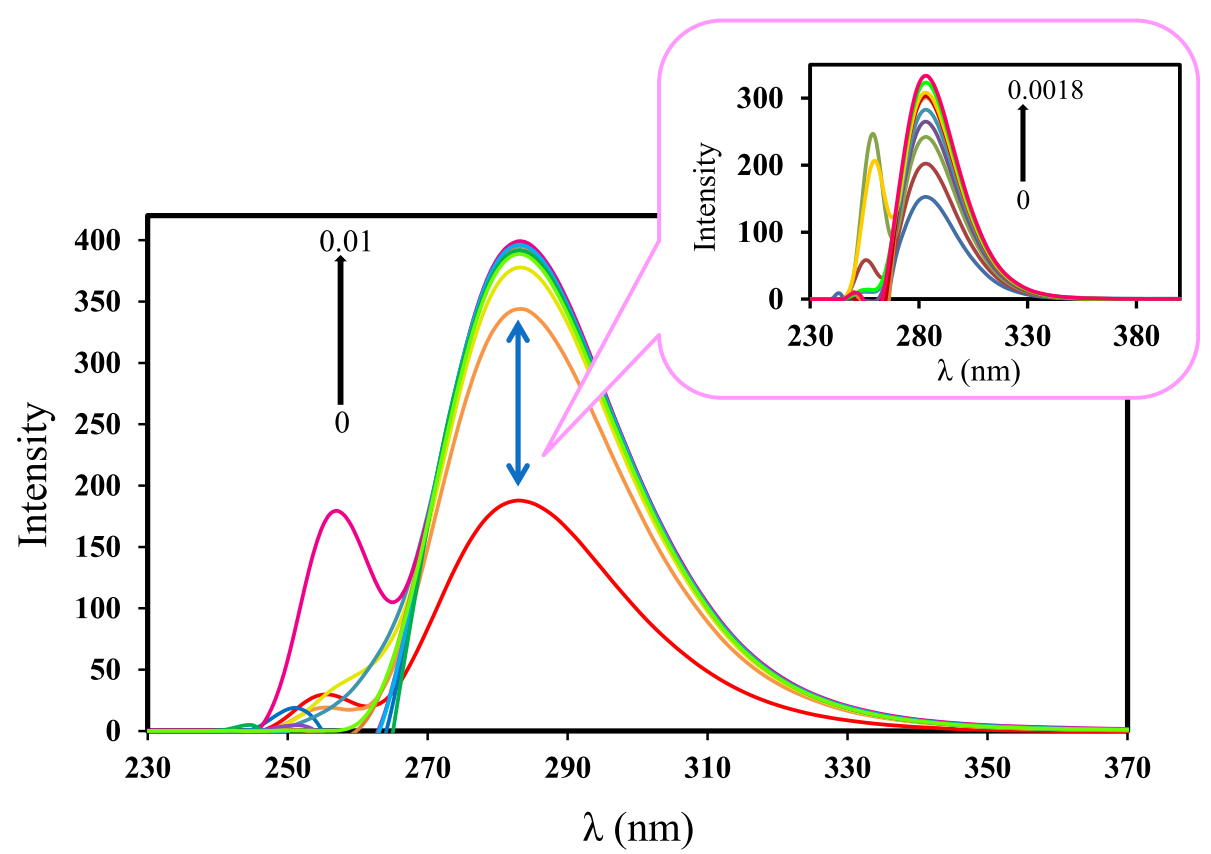

Figure 4 Fluorescence spectra of Thp in the presence of SBE- $\beta-C D$. The concentration of Thp is $5.0 \times 10^{-4} \mathrm{~mol} / \mathrm{L}$ and concentrations of SBE- $\beta$-CD are $0,0.1,0.2,0.3,0.4,0.5,0.6,0.7,0.8,0.9,1.0 \times 10^{-2} \mathrm{~mol} / \mathrm{L}$ from bottom to top in 10:90 (v/v) ethanol/50 mmol phosphate buffer solution. Inset shows fluorescence spectra in the presence of SBE- $\beta$-CD concentrations from bottom to top are $0,0.2,0.4,0.6,0.8,1.0,1.2,1.4,1.6$ and $1.8 \times 10^{-3} \mathrm{~mol} / \mathrm{L}$. 
Table 2 Regression parameters and formation constants $\left(K_{c}\right)$ for Thp/CD complexes as determined from spectra acquired in a $10 \%(\mathrm{v} / \mathrm{v})$ ethanol phosphate solution

\begin{tabular}{lllll}
\hline $\mathrm{CD}$ & Slope & Intercept & $\mathbf{R}^{\mathbf{2}}$ & $\boldsymbol{K}(\mathbf{L} / \mathbf{m o l})$ \\
\hline$\beta-C D^{*}$ & $6.4 \times 10^{-3}$ & 7.74 & 0.996 & $1200 \pm 40$ \\
HP- $\beta-$ CD $^{* *}$ & $5.4 \times 10^{-3}$ & 3.78 & 0.992 & $700 \pm 20$ \\
Me- $\beta-C D^{* *}$ & $5.0 \times 10^{-3}$ & 3.87 & 0.972 & $770 \pm 40$ \\
SBE- $\beta-C D^{* *}$ & $1.9 \times 10^{-3}$ & 4.41 & 0.967 & $2300 \pm 200$ \\
\hline
\end{tabular}

${ }^{*}[\mathrm{CD}]=0-0.002 \mathrm{~mol} / \mathrm{L},{ }^{* *}[\mathrm{CD}]=0-0.01 \mathrm{~mol} / \mathrm{L}$.

of the other Thp/CD complexes. Because SBE- $\beta$-CD has sulfobutylether chains on both sides of $C D$ rings, it has large hydrophobic space than the other derivatives of CDs, it would solubilize Thp. Furthermore, the end of sulfobutylether chain is anionic ion, which also increase the solubility of Thp/SBE- $\beta$-CD complex. Therefore, the structure of Thp/SBE- $\beta$-CD complex was investigated.

\section{Structure of the inclusion complex}

Figures 5(a to c) present the ${ }^{1} \mathrm{H}$ NMR spectra of Thp, SBE- $\beta$-CD and the Thp/SBE- $\beta$-CD complex respectively, acquired in $\mathrm{CD}_{3} \mathrm{OD}$ (Thp) and $\mathrm{D}_{2} \mathrm{O}$ (SBE- $\beta-\mathrm{CD}$ and Thp/SBE- $\beta$-CD). The presence of peaks attributable to Thp in Figure 5(c) demonstrates the successful formation of the complex.

Figure 6 shows the ${ }^{1} \mathrm{H}_{-}{ }^{1} \mathrm{H}$ ROESY NMR spectrum of the Thp/SBE- $\beta$-CD inclusion complex. This spectrum exhibits correlations between the signals at 7.39, 7.28 and $7.29 \mathrm{ppm}$ (assigned to $\mathrm{H}_{\mathrm{a}}, \mathrm{H}_{\mathrm{b}}$ and $\mathrm{H}_{\mathrm{c}}$ of Thp based on ${ }^{1} \mathrm{H}_{-}{ }^{1} \mathrm{H}$ COSY NMR) and those at $3.7 \mathrm{ppm}(\mathrm{H}-3$ and $\mathrm{H}-5$ of the SBE- $\beta-\mathrm{CD})$. These results indicate that the

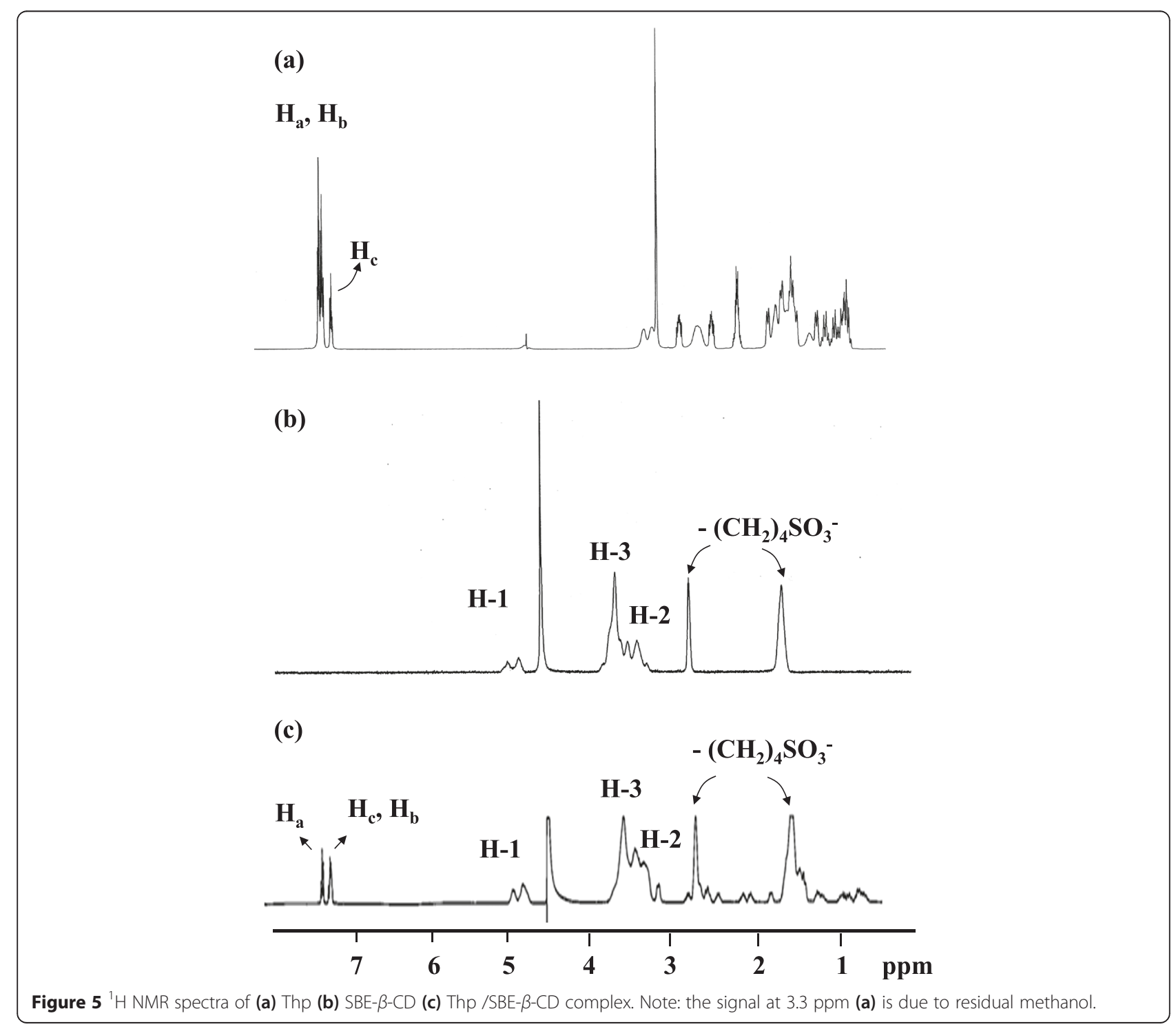




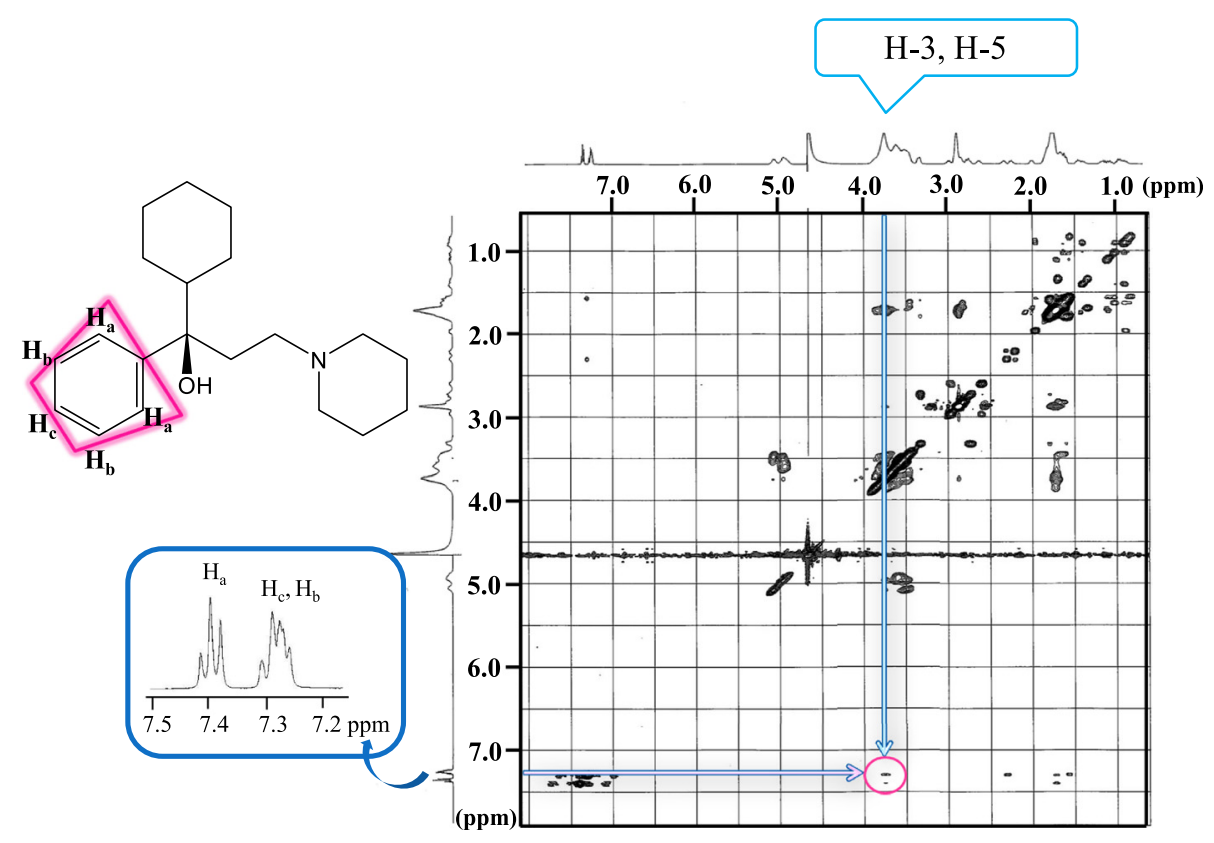

Figure $6{ }^{1} \mathrm{H}-{ }^{1} \mathrm{H}$ ROESY spectrum of the ThP/SBE- $\beta-\mathrm{CD}$ complex.

(a)

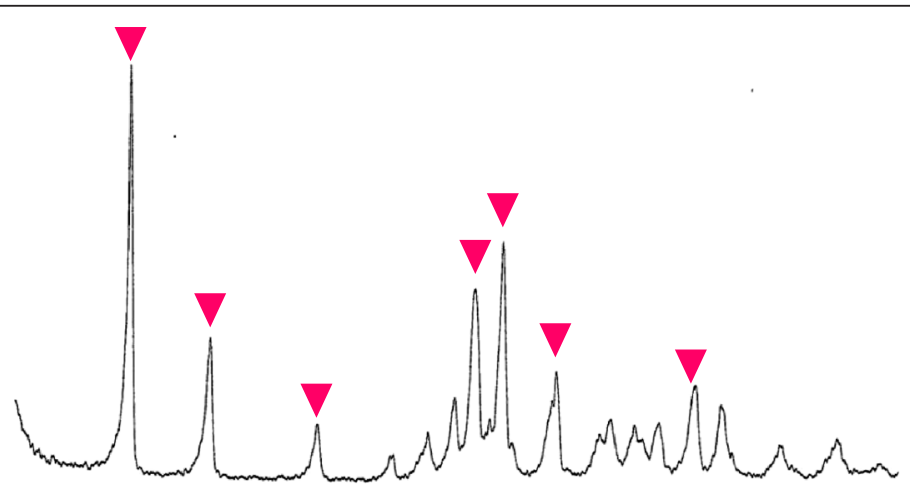

(b)

(c)

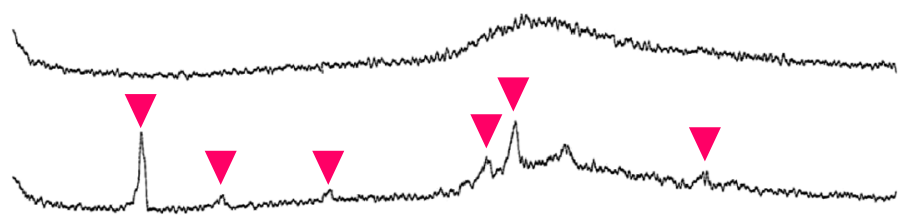

(d)

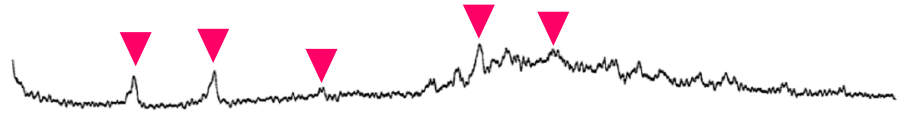

(e)

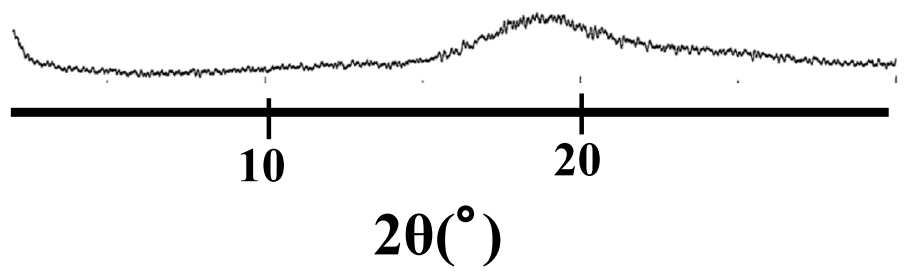

Figure 7 XRD patterns of (a) Thp, (b) SBE- $\beta$-CD and the Thp/SBE- $\beta$-CD (1:1) solid systems obtained by (c) physical mixing, (d) kneading and (e) freeze-drying. Red-down pointing triangle shows the peaks due to crystalline Thp. 
Thp phenyl group was incorporated into the cavity of the SBE- $\beta-C D$ complex, whereas the Thp cyclohexane ring and piperidine ring was not incorporated. From these data, the stoichiometry of the Thp/SBE- $\beta-C D$ complex was determined to be 1:1.

The above NMR data indicate that the Thp/SBE- $\beta-\mathrm{CD}$ complex consisted of an inclusion structure in the solution state. To further investigate this complex, a Thp/ SBE- $\beta$-CD solid complex was subsequently synthesized and characterized.

\section{Characterization of the Thp/SBE- $\beta-C D$ solid complex}

Figure 7 presents the XRD patterns of Thp, SBE- $\beta$-CD and the Thp/SBE- $\beta$-CD (1:1) solid systems obtained by physical mixing, kneading and freeze-drying methods. In Figure $7(\mathrm{a})$, seven characteristic diffraction peaks resulting from crystalline Thp are present at $2 \theta$ values of $5.69,8.21$, $11.6,16.6,17.5,19.2$ and $23.6^{\circ}$. In contrast, the XRD pattern of SBE- $\beta$-CD (Figure $7(\mathrm{~b})$ ) shows a broad diffraction profile because the solid material is amorphous due to the random substitution pattern of the sulfobutylether groups.
The solid systems obtained by physical mixing and kneading (Figures 7 (c and d)) show six peaks at $2 \theta$ values of $6.07,8.64,12.1,17.1,17.9$ and $24.0^{\circ}$, and five peaks at $2 \theta$ values of $5.85,8.40,11.9,16.8$ and $19.1^{\circ}$ due to crystalline Thp, respectively. The solid obtained by the freeze-drying method, however, (Figure 7(e)) exhibits an amorphous state. These data suggest that the solid complex was obtained via freeze-drying and that Thp was included in the SBE- $\beta$-CD cavities.

Figure 8 shows the DSC curves obtained for Thp, SBE- $\beta-C D$ and the Thp/SBE- $\beta$-CD (1:1) solid complexes obtained by the physical mixing, kneading and freezedrying methods. An endothermic peak at approximately $256^{\circ} \mathrm{C}$, corresponding to the melting point of Thp, is observed in the Thp curve (Figure 8(a)), as well as for the solid systems obtained by physical mixing (Figure 8(c)) and kneading (Figure $8(\mathrm{~d})$ ). The melting points of the physically mixed and kneaded materials were 229.5 and $231.5^{\circ} \mathrm{C}$, respectively. An endothermic peak representing the decomposition of SBE- $\beta$-CD can be seen at approximately $260^{\circ} \mathrm{C}$ in Figure $8(\mathrm{~b})$, as well as in the curves

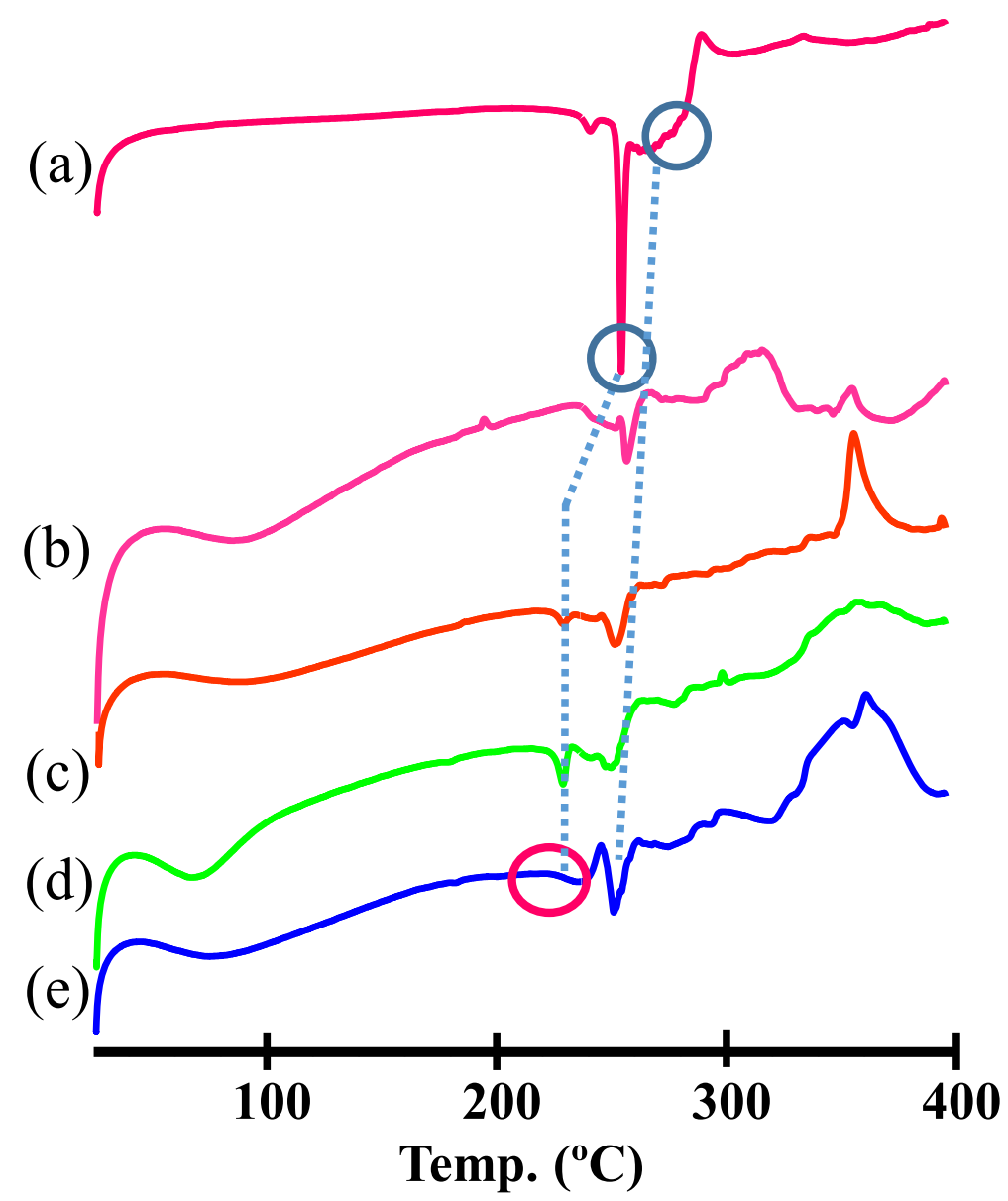

Figure 8 DSC curves of (a) Thp, (b) SBE- $\beta-C D$ and Thp/SBE- $\beta-C D$ (1:1) solid systems obtained by (c) physical mixing, (d) kneading and (e) freeze-drying. 
obtained from the physically mixing, kneaded and freezedried samples (Figures 8(c to e)). The decomposition points of the solid systems obtained by the physical mixing, kneading and freeze-drying methods were 253.7, 256.9 and $253.9^{\circ} \mathrm{C}$, respectively.

In the case of the freeze-dried solid complex, the endothermic peak corresponding to the melting of Thp is not present, suggesting that the Thp interacts with the SBE- $\beta$ $\mathrm{CD}$ in the solid state to form an inclusion complex.

These results demonstrate that the solid complex obtained by the freeze-drying method was completely different from the systems generated using physical mixing and kneading. The Thp evidently interacts with SBE- $\beta$-CD in the solid complex obtained by the freeze-drying method, forming an inclusion complex.

\section{Conclusion}

The effects of natural and various modified CDs on the solubility of Thp were assessed, using the solubility method. The solubility of Thp in the presence of SBE- $\beta$-CD was found to be increased significantly, by a factor of approximately 11 . The stoichiometry of each $\mathrm{Thp} / \mathrm{CD}$ complex was observed to be 1:1. In the case of the Thp/SBE- $\beta$-CD inclusion complex, the formation constants $\left(K_{c}\right)$ obtained by fluorometry was $2300 \mathrm{~L} / \mathrm{mol}$. The phenyl groups of the Thp were found to be included in the SBE- $\beta$-CD cavities. Finally, the freeze-drying method was determined to successfully generate solid inclusion complexes.

Competing interests

The authors declare that they have no competing interests.

\section{Authors' contributions}

$\mathrm{HM}$ and HN designed the research; RT performed the experiments; HM and $\mathrm{HN}$ analyzed the data; HM wrote the manuscript. All authors read and approved the final manuscript.

\section{Acknowledgements}

The authors thank Assistant Professor C. Tode of Kobe Pharmaceutical University for the measurements of ${ }^{1} \mathrm{H}-{ }^{1} \mathrm{H}$ COSY and ${ }^{1} \mathrm{H}-{ }^{1} \mathrm{H}$ ROESY NMR spectra.

Received: 3 February 2015 Accepted: 17 April 2015

Published online: 07 May 2015

\section{References}

Ali SM, Shamim S (2014) Structure elucidation of benzhexol- $\beta$-cyclodextrin complex in aqueous medium by ${ }^{1} \mathrm{H}$ NMR spectroscopic and computational methods. J Encapsul Adsorption Sci 4:63-70

Al-Rawashdeh NAF, Al-Sadeh KS, Al-Bitar MB (2010) Physicochemical study on microencapsulation of hydroxypropyl- $\beta$-cyclodextrin in dermal preparations. Drug Dev Ind Pharm 36(6):688-697

Al-Rawashdeh NAF, Al-Sadeh KS, Al-Bitar MB (2013) Inclusion complexes of sunscreen agents with $\beta$-cyclodextrin: spectroscopic and molecular modeling studies. J Spectrosc. doi:10.1155/2013/841409

Alvarez-Parrilla E, De La Rosa LA, Torresrivas F, Rodrigo-Garcia J, González-Aguilar GA (2005) Complexation of apple antioxidants: chlorogenic acid, quercetin and rutin by $\beta$-cyclodextrin ( $\beta$-CD). J Ind Phenom Maclocycl Chem 53:121-129

Benesi HA, Hildebrand $\mathrm{JH}$ (1949) A spectrophotometric investigation of the interaction of iodine with aromatic hydrocarbons. J Am Chem Soc 89:2703-2707
Haiyun D, Jianbin C, Guomei Z, Shaomin S, Jinhao P (2003) Preparation and spectral investigation on inclusion complex of $\beta$-cyclodextrin with rutin. Spectrochimica Acta Part A125:3421-3429

Hamai S (1982) Association of inclusion compounds of $\beta$-cyclodextrin in aqueous solution. Bull Chem Soc Jpn 55:2721-2729

Hibi T, Tatsumi M, Hanabusa M, Higuchi R, Imai T, Otagiri M, Uekama K (1984) Stabilization and reduction of irritant taste of anti-inflammatory drug pirprofen by $\beta$-cyclodextrin complexation. Yakugaku Zasshi 104(9):990-996

Higuchi T, Connors KA (1965) Phase-solubility techniques. Adv Anal Chem Instrum 4:117-212

Job P (1928) Formation and stability of inorganic complexes in solution. Ann Chem 9:113-203

Kondo H, Nakatani H, Hiromi K (1976) Interaction of cyclodextrins with fluorescent probes and its application to kinetic studies of amylase. J Biochem 79:393-405

Loftsson T, Duchêne D (2007) Cyclodextrins and their pharmaceutical applications. Int J Pharm 329:1-11

Maeda H, Onodera T, Nakayama H (2010) Inclusion complex of $a$-lipoic acid and modified cyclodextrins. J Incl Phenom Macrocycl Chem 68:201-206

Maeda H, Ogawa Y, Nakayama H (2013) Inclusion complex of melatonin and modified cyclodextrins. J Incl Phenom Macrocycl Chem 78:217-224

Mulisa E, Ndorbor T, Xiao D, He H (2014) Molecular docking method for the prediction of enantiorecognition of trihexyphenidyly and its derivatives on carboxy methyl-cylodextrins. Ind J Sci Res Tech 2(2):31-37

Ono N, Miyamoto Y, Ishiguro T, Motoyama K, Hirayama F, lohara D, Seo H, Tsuruta S, Arima H, Uekama K (2011) Reduction of bitterness of antihistaminic drugs by complexation with $\beta$-cyclodextrin. J Pharm Sci 100(5):1935-1943

ÖZdemir N, Ordu \$̧ (1998) Improvement of dissolution properties of furosemide by complexation with $\beta$-cyclodextrin. Drug Dev Ind Pharm 24:19-25

Reineccius TA, Reineccius GA, Peppard TL (2002) Encapsulation of flavors using cyclodextrins: comparison of flavor retention in alpha, beta, and gamma types. J Food Sci 67:3271-3279

Saenger W (1980) Cyclodextrin inclusion compounds in research and industry. Angew Chem Int Ed Engl 19:344-362

Szejtli J (1992) The properties and potential uses of cyclodextrin derivatives. J Inclusion Phenom Mol Recognit Chem 14:25-36

Uekama K (1985) Pharmaceutical applications of methylated cyclodextrins. Pharm Int 6:61-65

\section{Submit your manuscript to a SpringerOpen ${ }^{\odot}$ journal and benefit from:}

- Convenient online submission

- Rigorous peer review

- Immediate publication on acceptance

- Open access: articles freely available online

- High visibility within the field

Retaining the copyright to your article

Submit your next manuscript at $>$ springeropen.com 